\title{
Development of contact irreversible electroporation using a comb-shaped miniature electrode
}

\author{
Shuto YOSHIMATSU*, Masahiro YOSHIDA*, Kosaku KURATA** and Hiroshi TAKAMATSU** \\ *Graduate School of Engineering, Kyushu University \\ 744 Motooka, Nishi-ku, Fukuoka 819-0395, Japan \\ **Department of Mechanical Engineering, Kyushu University \\ 744 Motooka, Nishi-ku, Fukuoka 819-0395, Japan \\ E-mail: kurata@mech.kyushu-u.ac.jp
}

Received: 19 December 2016; Revised: 12 May 2017; Accepted: 17 August 2017

\begin{abstract}
Irreversible electroporation (IRE) has been studied as a less invasive method for tumor treatment. Since the mechanism of the treatment is based on the fatal perforation of the cell membrane caused by an external electric field, a tumor can be ablated non-thermally if an appropriate electric field is selected. However, an electric field more than a few $\mathrm{kV} / \mathrm{cm}$ is required to accomplish ablation. In this study, we aim to examine the feasibility of a comb-shaped miniature electrode for reducing the required voltage for IRE. The reduction of the applied voltage while maintaining the potential difference was realized by narrowing the gap between the electrodes. A $150-\mu \mathrm{m}$-wide miniature electrode with a $100-\mu \mathrm{m}$ gap between its teeth was fabricated using photolithography. In the experiment, the electrode was contacted onto a tissue phantom consisting of fibroblasts cultured in agarose gel three-dimensionally. After the application of electric pulses, cell ablation depth was examined using fluorescent staining. The miniature electrode successfully ablated the cells at the surface of the tissue phantom by the application of 90 electric pulses at $100 \mathrm{~V}$. The maximum and average ablation depth were $72.7 \mu \mathrm{m}$ and $61.0 \pm 11 \mu \mathrm{m}$, respectively, which was approximately $40 \%$ of that estimated by the numerical analysis. Our study showed that the contact-IRE using a miniature electrode in the order of sub-millimeter does ablate the superficial cells of targeted tissues upon the application of electric pulses of less than $100 \mathrm{~V}$; however, further studies are required to maximize the ablation depth under the constraint of limited applied voltage.
\end{abstract}

Key words : Irreversible electroporation, Electric field, Finite element analysis, Tissue ablation, Cell necrosis

\section{Introduction}

Electroporation is a technique to increase the permeability of the cell membrane by using electric pulses. When an external electric field is applied to the cell, nanopores are generated on the cell membrane. These pores are repaired promptly after the electric field is turned off. This phenomenon facilitates the cellular introduction of macromolecules and therefore, it has been used as an essential tool in the fields of biotechnology and biomedicine (Fromm et al., 1986, Jastreboff et al., 1987, Neumann et al., 1982, Riggs and Bates, 1986).

Electroporation has also been studied as a tool for cancer treatment. In electrochemotherapy (ECT), electroporation is used to introduce various impermeable chemotherapeutic drugs into tumor cells through an electroporated cell membrane (Mir et al., 1991, Quaglino et al., 2008). Since the permeable membrane recovers after treatment, an anticancer effect is expected to originate exclusively from the chemotherapeutic drugs.

On the other hand, a new cancer therapy by electroporation without any drugs was proposed by Davalos et al (Davalos et al., 2005). In their method, the cells were exposed to the pulsed electric field over a certain threshold. The cell membrane was irreversibly damaged, which led to necrotic cell death. This is called irreversible electroporation (IRE). Needle-like electrodes, plates, and clamp electrodes are commonly used to deliver the electric pulses to tumors. 
The advantage of the IRE is not only that no chemotherapeutic drugs are required, but also that the treatment is based on the membrane perforation and is free from thermal effects if the appropriate pulse conditions are selected. This aspect is significantly different from conventional thermal therapies such as radiofrequency ablation (Brace, 2009), high-intensity focused ultrasound treatment (Dubinsky et al., 2008, Murat et al., 2007), and cryosurgery (Baust et al., 1997, Gage and Baust, 1998). However, the IRE treatment should apply a considerably high voltage of more than a few $\mathrm{kV} / \mathrm{cm}$ to the electrodes, which causes convulsions and contractions of muscles. Therefore, general anesthesia is required during the treatment to avoid the discomfort of patients.

According to many previous studies, the potential difference required for breakdown of the cell membrane ranges from 0.5 to 2 V (Abidor et al., 1979, Glaser et al., 1988, Kinosita et al., 1988, Melikov et al., 2001, Riemann et al., 1975, Sale and Hamilton, 1968, Teissie and Rols, 1993, Zimmermann et al., 1974). Thus, the reduction of the applied voltage while maintaining the aforementioned potential difference can be realized by narrowing the gap between the electrodes. In this study, we aim to examine the feasibility of a miniature electrode with a narrow gap for reducing the required voltage for IRE. Prior to the experiment, the expected ablation depth was calculated by finite element analysis according to the aforementioned criteria i.e., the magnitude of the transmembrane potential determines the irreversible cell breakdown. Based on the analytical results, a comb-shaped electrode was fabricated using photolithography. In the experiment, the electrode was placed in contact with a tissue phantom consisting of fibroblasts cultured in agarose gel three-dimensionally. After the application of electric pulses, cell ablation depth was examined using fluorescent staining and compared with the analysis.

\section{Materials and methods}

\subsection{Analytical model}

The configuration of the analytical model is shown in Fig. 1. The comb-shaped miniature electrode with width $w$ and gap distance between the teeth $l$ was placed in contact with a uniform tissue with the electric conductivity $\sigma$. Considering the geometrical symmetry, the area enclosed by the broken line in Fig. 1 is defined as a solution domain.

When the voltage $V$ is applied between the electrodes, the distribution of electric potential $\phi$ can be calculated by solving the following Laplace equation:

$$
\frac{\partial}{\partial x}\left(\sigma \frac{\partial \phi}{\partial x}\right)+\frac{\partial}{\partial z}\left(\sigma \frac{\partial \phi}{\partial z}\right)=0
$$

with the boundary conditions

$$
\phi=V / 2
$$

at the surface of the anode,

$$
\phi=-V / 2
$$

at the surface of the cathode, and

$$
\partial \phi / \partial x=0
$$

at the right edge of the solution domain. At the left edge of the solution domain,

$$
\phi=0
$$

because the absolute value of the electric potential is symmetric, but its sign is opposite at the centerline between the

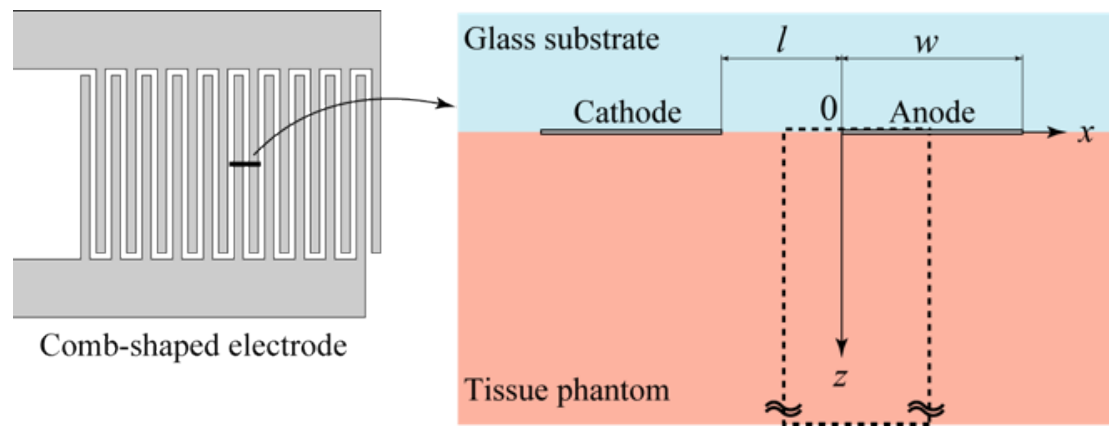

Fig. 1 Schematic representation of comb-shaped miniature electrode and analytical model. Solution domain for the finite element analysis is described as the area enclosed by the broken line. 
anode and cathode. The remaining outer edge of the solution domain is assumed to be

$$
\partial \phi / \partial z=0
$$

The governing equation (1) is described in the non-dimensional form as

$$
\frac{\partial^{2} \Phi}{\partial X^{2}}+\frac{\partial^{2} \Phi}{\partial Z^{2}}=0
$$

where

$$
\begin{aligned}
& X=x / w \\
& Z=z / w \\
& \Phi=\phi /(V / 2)
\end{aligned}
$$

The boundary conditions, Eqs. (2)-(6), are described, respectively, in the non-dimensional form as follows:

$$
\Phi=1
$$

at the surface of the anode,

$$
\Phi=-1
$$

at the surface of the cathode,

$$
\partial \Phi / \partial X=0
$$

at the right edge of the solution domain,

$$
\Phi=0
$$

at the left edge of the solution domain, and

$$
\partial \Phi / \partial Z=0
$$

at the remaining outer edge of the solution domain.

The analysis was conducted for the geometry of $w=150 \mu \mathrm{m}$ and $l=100 \mu \mathrm{m}(L=l / w=2 / 3)$. The height of the solution domain was $800 \mu \mathrm{m}$, which is less than the thickness of the tissue phantom; however, it was sufficiently thick such that the change in the height of the domain did not affect the distribution of the electric potential. The solution domain was divided by approximately 11,300 triangular elements with 5,600 nodes. The numerical solution was obtained using the finite element analysis program Marc and the pre/post-processing software Mentat (MSC Software Corp., Santa Ana, CA). The electric conductivity of the tissue $(1.82 \mathrm{~S} / \mathrm{m}$ ) was obtained from the literature (Mazzoleni et al., 1986).

\subsection{Fabrication of the comb-shaped miniature electrode}

The comb-shaped miniature electrode was fabricated using photolithography. A glass coverslip with a diameter of $25 \mathrm{~mm}$ was coated using an image reversal photoresist (AZ5214E, Clarient K.K., Tokyo, Japan) and exposed to UV light while covered by an electrode-patterned photomask. After baking, the unexposed regions were washed away. A thin film of titanium $(8 \mathrm{~nm})$, and subsequently platinum $(40 \mathrm{~nm})$, were deposited on the patterned substrate. Finally, the remaining photoresist was removed.

Figure 2 shows the fabricated miniature electrode. It has 10 pairs of $154-\mu \mathrm{m}$-wide teeth with a gap of $100 \mu \mathrm{m}$ that were measured using a stereoscopic microscope. The approximate size of the entire electrode was $3 \mathrm{~mm} \times 5 \mathrm{~mm}$.

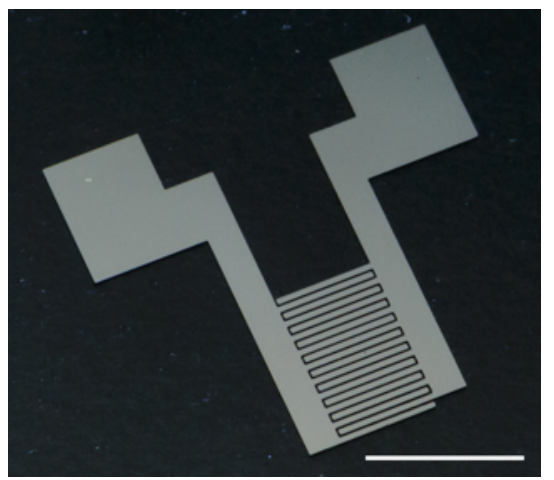

Fig. 2 Micrograph of the comb-shaped miniature electrode fabricated using photolithography. Scale bar: $5 \mathrm{~mm}$. 


\subsection{Cell culture experiment}

Electroporation experiments were conducted with 3D cultured cells as the tissue phantom. NIH3T3-3 mouse fibroblast cells (Riken Cell Bank, Tsukuba, Japan) were routinely maintained in cell culture dish of diameter $150 \mathrm{~mm}$ with $\alpha$-MEM ( $\alpha$-minimum essential medium, Wako Pure Chemical Industries, Ltd., Osaka, Japan) supplemented with $10 \%$ fetal bovine serum (FBS, Biowest, Nuaillé, France) and $1 \%$ penicillin and streptomycin (Wako Pure Chemical Industries, Ltd.) in a $\mathrm{CO}_{2}$ incubator $\left(5 \% \mathrm{CO}_{2}, 37^{\circ} \mathrm{C}\right)$.

An aqueous solution of the tissue phantom was prepared by mixing $2 \mathrm{wt} \%$ agarose solution (SeaPlaque Agarose, Lonza Rockland, Inc., ME), 10× $\alpha$-MEM, $260 \mathrm{mM}$ sodium hydrogen carbonate buffer, and cell suspension at the volume ratio of $8: 1: 1: 5$. The cell density was $2 \times 10^{6}$ cells $/ \mathrm{ml}$. After centrifugation for $4 \mathrm{~min}$ at $500 \mathrm{rpm}$ to increase the cell density at the surface, the tissue phantom was solidified at $4^{\circ} \mathrm{C}$ for $20 \mathrm{~min}$. It was placed in a $\mathrm{CO}_{2}$ incubator at $37^{\circ} \mathrm{C}$ before use.

The tissue phantom was placed in contact with the comb-shaped electrode, and was subjected to 90 electric pulses of $50 \mathrm{~V}$ or $100 \mathrm{~V}$ using a square wave generator (ECM830, Harvard Apparatus, Holliston, MA). The fixed pulse conditions of pulse lengths of $100 \mu \mathrm{s}$ at interval of $1 \mathrm{~s}$ were selected in this study according to the clinical studies of IRE therapy targeted to solid cancers (Ball et al., 2010, Thomson et al., 2011).

After the pulse application, 1-mm-thick longitudinal sections of the tissue phantom were sliced and stained with 10 $\mu \mathrm{g} / \mathrm{ml}$ calcein-AM (Dojindo Laboratories, Kumamoto, Japan) and $5 \mu \mathrm{g} / \mathrm{ml}$ propidium iodide (PI, Molecular Probes, Thermo Fisher Scientific, Waltham, MA) for $30 \mathrm{~min}$ to examine the cell viability in the depth direction. The stained slices were observed by using a confocal laser scanning microscope system (A1R+, Nikon, Tokyo, Japan). The cell experiments were repeated at least three times.

\subsection{Evaluation of thermal damage}

In order to evaluate the risk of thermal damage during contact IRE, temperature rise owing to Joule heating was measured by using a temperature-sensitive ink (Kurata et al., 2012). The temperature-sensitive ink was collected from an erasable ballpoint pen (FriXion Erasable Rollerball Pen, PILOT Corporation, Tokyo, Japan) and mixed in an agarose gel at the concentration of $1 \%$. After gelation, the gel was exposed to the electric pulses under the same conditions as described above. According to our previous study (Kurata et al., 2017), the color of the ink in the agarose gel starts fading at $53.5^{\circ} \mathrm{C}$ and completely disappears at $57.5^{\circ} \mathrm{C}$. The change in color was observed using a digital microscope (VHX-1000, Keyence, Osaka, Japan).

\section{Results}

Figure 3 shows the distribution of the non-dimensional electric potential. The electric potential underneath the electrode exhibited hemispherical distribution. It reduced drastically near the surface of the tissue phantom, resulting in a significantly larger gradient near the edge of the electrode.

Figures 4 (a) and (b) show the distribution of the non-dimensional electric field $|\nabla \Phi|$ calculated by

$$
|\nabla \Phi|=\sqrt{\left(\frac{\partial \Phi}{\partial X}\right)^{2}+\left(\frac{\partial \Phi}{\partial Z}\right)^{2}}
$$

The electric field was the highest at the edge of the electrode and decreased as a function of depth.

If we hypothesize that a spherical cell with a radius of $r$ is exposed to a uniform electric field $\nabla \phi$, the transmembrane potential $V_{\mathrm{m}}$ is given by the Schuwan equation:

$V_{\mathrm{m}}=1.5 \cdot \nabla \phi \cdot r \cos \theta$

where $\theta$ is the angle between the applied electric field and the segment from the center of the cell to the point of interest (Zimmermann et al., 1974). Assuming that irreversible breakdown of the cell occurs when $V_{\mathrm{m}}$ reaches the critical transmembrane potential $V_{\mathrm{m}, \mathrm{cr}}(\approx 1 \mathrm{~V}$ from the literature (Abidor et al., 1979, Glaser et al., 1988, Kinosita et al., 1988, Melikov et al., 2001, Riemann et al., 1975, Sale and Hamilton, 1968, Teissie and Rols, 1993, Zimmermann et al., 1974)), the critical electric field $\nabla \phi_{\mathrm{cr}}$ and the non-dimensional critical electric field $\nabla \Phi_{\mathrm{cr}}$ necessary for IRE are respectively calculated by 


$$
\begin{aligned}
\nabla \phi_{\mathrm{cr}} & =\frac{V_{\mathrm{m}, \mathrm{cr}}}{1.5 \cdot\left(d_{\mathrm{cell}} / 2\right)} \\
\nabla \Phi_{\mathrm{cr}} & =\frac{V_{\mathrm{m}, \mathrm{cr}} \cdot w}{1.5 \cdot(V / 2) \cdot\left(d_{\text {cell }} / 2\right)}
\end{aligned}
$$

Thus, the ablation depth can be determined from Fig. 4 for arbitrary values of the applied voltage $V$ and electrode width $w$.

Figure 5 shows the estimated ablation depth $d_{\mathrm{ab}}$ for fibroblast (average cell diameter $d_{\text {cell }}=16.6 \mu \mathrm{m}$ ) as a function of the applied voltage $V$ at the edge of the 150- $\mu$ m-wide electrode and the center of the electrode. The ablation depths at both places monotonically increased with the applied voltage and were consistent with each other at $V>60 \mathrm{~V}$. The estimated ablation depth at $100 \mathrm{~V}$, for instance, was $176 \mu \mathrm{m}$ independent of the place. However, the difference was observed at a lower voltage. At the center of the electrode, the voltage threshold, $18.4 \mathrm{~V}$, exists for the initiation of cell

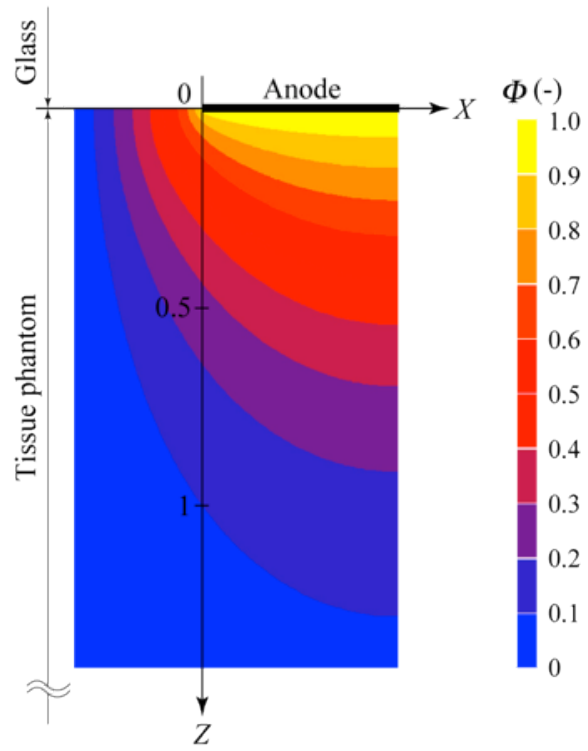

Fig. 3 Distribution of non-dimensional electric potential. The thick black line indicates the position of the electrode.

(a)

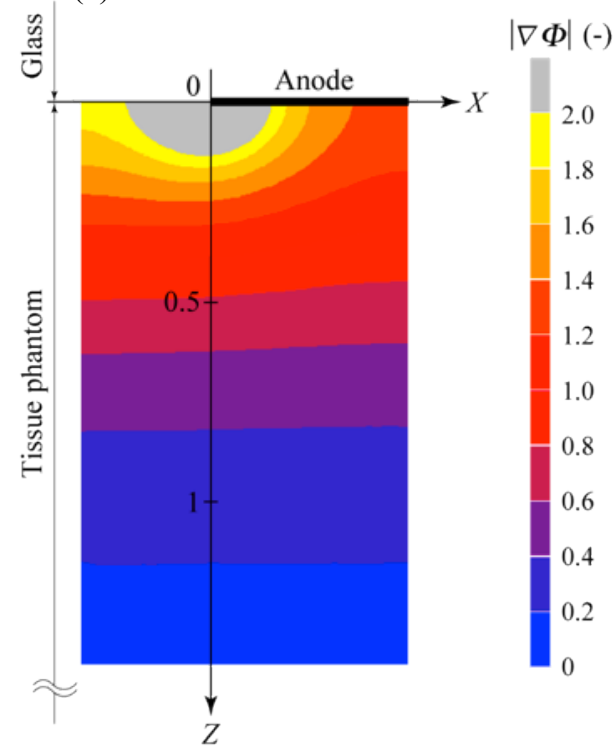

(b)

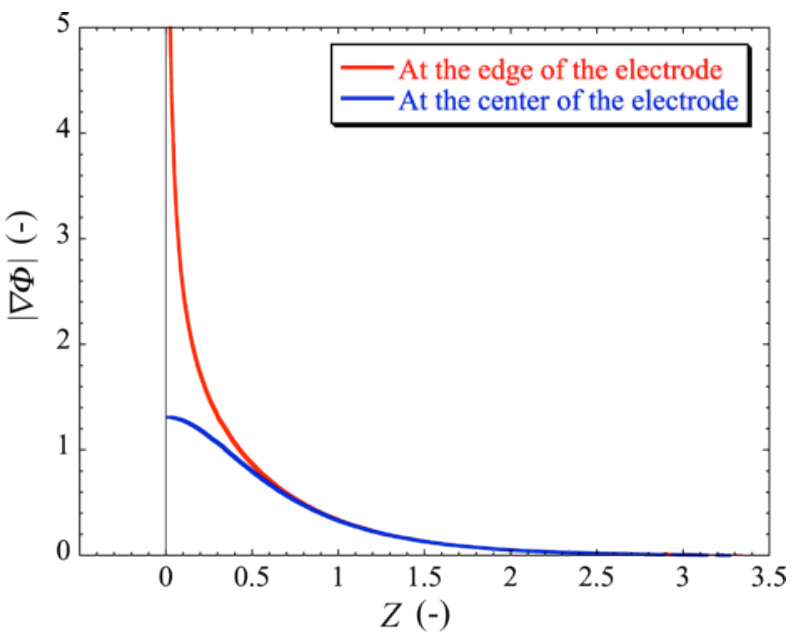

Fig. 4 (a) Distribution of non-dimensional electric field. The thick black line indicates the position of the electrode. (b) Non-dimensional electric field at the edge and center of the electrode as a function of depth. 
ablation because the electric field was considerably smaller than that at the edge as shown in Fig. 4 . This is attributed to the distorted contour of the field strength at a higher electric field as shown in Fig. 4(a).

The experimental results are demonstrated using the fluorescent micrographs of the longitudinal sections of the tissue phantom in Fig. 6. Calcein-positive green cells show that the round cells were distributed within the tissue phantom. In the control sample (Fig. 6(a)), which was not subjected to pulse application, most of the cells were calcein-positive (green), indicating that they were alive. The application of the electric pulses at $50 \mathrm{~V}$ induced PI-positive (red) cells, which were dead, at the surface of the tissue phantom (Fig. 6(b)). However, the necrotized cells were confined to the outermost surface of the tissue. In contrast, almost all the cells at the surface were dead in the tissue exposed to the electric pulses at $100 \mathrm{~V}$ (Fig. 6(c)). The maximal and average ablation depth measured from the micrographs were $72.7 \mu \mathrm{m}$ and $61.0 \pm 11 \mu \mathrm{m}$, respectively.

A tissue phantom with a temperature-sensitive ink demonstrated no obvious change in the color after the application of the electric pulses at $50 \mathrm{~V}$ and $100 \mathrm{~V}$. The results indicate that no thermal damage is induced as long as these pulse parameters are selected.

\section{Discussion}

In this study, the feasibility of a miniature electrode with a narrow gap was examined for reducing the required voltage for IRE. A $150-\mu \mathrm{m}$-wide comb-shaped electrode with a $100-\mu \mathrm{m}$ gap between its teeth was fabricated using photolithography. The miniature electrode did ablate the cells at the surface of the tissue phantom by the application of repetitive electric pulses at $100 \mathrm{~V}$.

The shape of the ablation region was consistent well with the contour lines of the electric field; the maximum

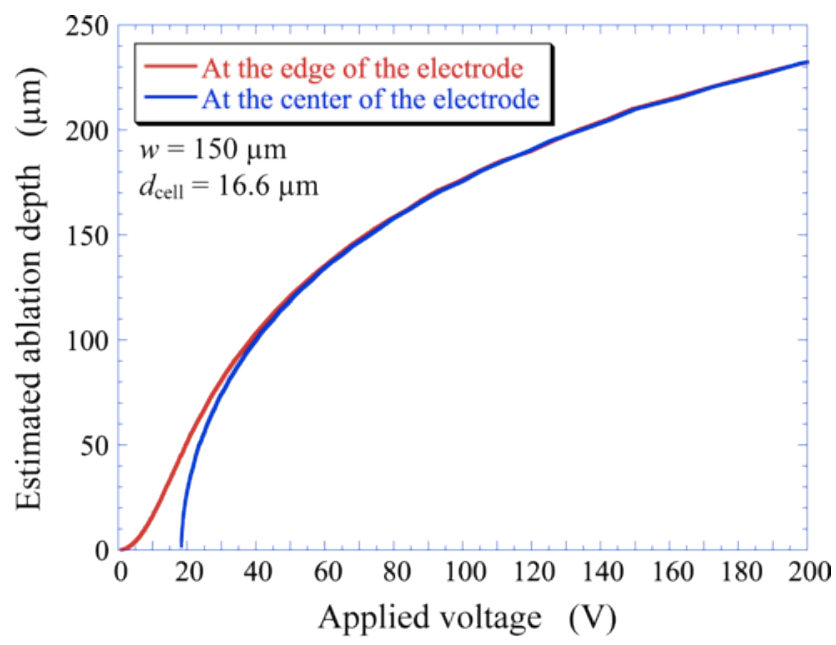

Fig. 5 Estimated ablation depth at the edge of the electrode and immediately below the center of the electrode as a function of the applied voltage.

(a)

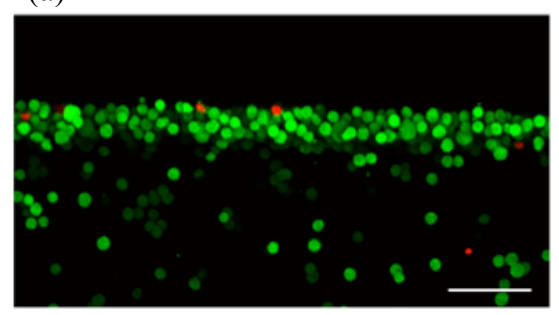

(b)

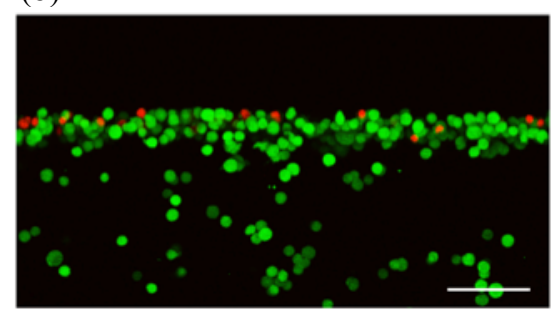

(c)

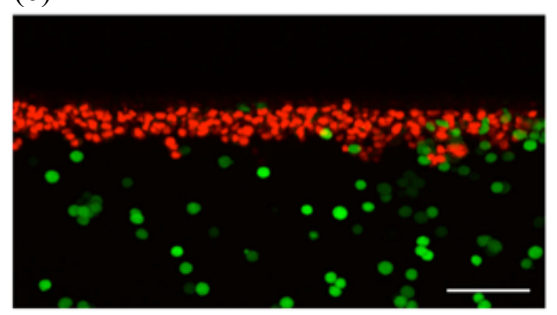

Fig. 6 Fluorescent micrographs of the tissue phantoms (vertical cross-section). Viable cells emit green fluorescence of calcein-AM whereas nuclei of dead cells are stained in red by propidium iodide.

(a) Control without the application of electric pulses, (b) the phantom exposed to 90 pulses at 50 $\mathrm{V}$ and, (c) $100 \mathrm{~V}$. Scale bar: $100 \mu \mathrm{m}$. 
ablation depth was obtained at the edge of the electrode, whereas the ablation region had a dent just underneath the electrode. However, the maximum ablation depth of $72.7 \mu \mathrm{m}$ obtained by the experiment at $100 \mathrm{~V}$ was $58.7 \%$ smaller than that estimated by the numerical analysis. In the experiment using the applied voltage of $50 \mathrm{~V}$, only cells on the outermost surface were necrotized, which was inconsistent with the analysis. One of the possible reasons is that the expected electric potential was not applied to the tissue phantom owing to the photolithographed electrode, which was only $48 \mathrm{~nm}$ thick. Since its electrical conductivity is smaller than that of a bulk material, the voltage drop in the electrode might reduce the effective voltage on the tissue phantom, thus decreasing the ablation depth.

The water trapped between the glass surface and tissue phantom at the electrode teeth may decrease the ablation depth. The electric current may not penetrate sufficiently deep into the tissue phantom if it short-circuits over the phantom surface between the teeth. In the numerical analysis, we ignored the space between the electrode teeth, and assumed that the potential difference was applied at the surface of the tissue phantom. Garcia-Sanchez et al. developed a surface electroporator with a spiral electrode pattern for in-situ gene transfection of adherent cell monolayers and reported that the insulation between the electrode teeth extensively enabled the increase of the electric field intensity around the cells (Garcia-Sanchez et al., 2012, Garcia-Sanchez et al., 2014). Filling the space with an insulator would increase the ablation depth in the experiment.

Another possible reason is the uncertainty of the assumed critical transmembrane potential $V_{\mathrm{m}, \mathrm{cr}}$ for IRE in Eqs. (18) and (19). Many previous studies reported that $V_{\mathrm{m}, \text { cr }}$ ranges from 0.5 to $2 \mathrm{~V}$ depending on the temperature (Abidor et al., 1979, Glaser et al., 1988, Kinosita et al., 1988, Melikov et al., 2001, Riemann et al., 1975, Sale and Hamilton, 1968, Teissie and Rols, 1993, Zimmermann et al., 1974). It also varies with the cell type (Polak et al., 2013). The estimated ablation depth is larger if $V_{\mathrm{m} \text {, cr }}$ is underestimated. The electrical conductivity of the tissue phantom also has an uncertainty owing to the dense distribution of the cells near the surface of the tissue phantom. In the cell experiment, the suspended cells were collected at the surface of the tissue phantom using centrifuging, which improved the accuracy of the measurement of the ablation depth near the surface. According to the confocal laser microscopic images, the cell density near the surface was approximately $3.6 \times 10^{8} \mathrm{cells} / \mathrm{ml}$, which almost corresponds to the hexagonal closest packing. The cell density near the surface is approximately 100 times higher than that deep inside the tissue phantom. However, the dense distribution of the cells could lead to heterogeneous electrical properties of the tissue phantom owing to the higher resistance of the cell membrane, which possibly results in a shallower ablation depth in the experiment as compared to the estimation obtained by the numerical analysis.

The dependence of the electroporation efficiency on the number of pulses would also be a cause of the difference between the experimental and analytical results. In the experiment, repetitive pulses induce the accumulation of membrane damage even if the electric field intensity is less than the threshold for the IRE. However, the numerical analysis we performed did not include the effect of multiple pulses; we assumed that the cell membrane is irreversibly damaged by a transmembrane potential above $1 \mathrm{~V}$. Since cell necrosis is the result of a dynamic process, it could not be fully described as a static problem. The combination of pulse width, intervals, and the number of repetitions has a considerable effect on the membrane destruction and resealing processes.

The comb-shaped miniature electrode successfully ablated the cells located approximately $70 \mu \mathrm{m}$ deep in the tissue phantom. The device is applicable for the treatment of skin and gastrointestinal surfaces because it is easily combined with a fiber gastroscope. However, the ablation depth is not sufficiently large to treat cutaneous and subcutaneous tumors such as malignant melanoma and gastrointestinal tumors. For instance, skin cancer first appears at the basal lamina, and subsequently invades into the epidermis and dermis. The basal lamina is a layer of the extracellular matrix that anchors epidermis, and is located at a depth of 100-200 $\mu \mathrm{m}$. Therefore, cell ablation in the order of a few hundreds of microns is required to treat skin cancer in the initial stage.

According to the numerical analysis, ablation depth monotonically increased with the applied voltage. The cell ablation in the order of a few hundreds of microns is accomplished by the applied voltage of more than $100 \mathrm{~V}$. The relationship between the analysis and experiment affected by the pulse condition is important for the future design of comb-shaped electrodes for IRE. However, this was not verified by experiments because damage to the electrode was observed after the application of electric pulses above $100 \mathrm{~V}$. The thinness of the electrode and weakness of adhesion at the electrode-glass interface probably caused the damage to the electrode. The photolithographed electrode requires improvement in durability. Further studies are required to fabricate a durable electrode and to maximize the ablation depth under the constraint of limited applied voltage.

The safety of the electric pulse depends on the magnitude, time, and pathway of the electric current flowing in the 
body. In general, the electric pulse is perceived when the current reaches $1 \mathrm{~mA}$. Tetanic muscle contraction occurs at 20 $\mathrm{mA}$, and ventricular fibrillation is induced by the application of current at $50 \mathrm{~mA}$ for $2 \mathrm{~s}$. The electric resistance of a human is sufficiently small to allow electric current to pass through the body via skin and limbs of the body (total electrical resistance: approximately $2 \mathrm{k} \Omega$ ). Based on the Ohm's law, the international safety standards and previous studies set the allowable voltage in the range of 25-50 V (Bernstein, 1994, Koumbourlis, 2002, Roberts, 2010). However, in the proposed contact IRE, the area in which the electric current flows is limited only to the superficial layer of the body. Thus, the risk of causing muscle contraction and ventricular fibrillation is probably very small even if the electric pulses above $100 \mathrm{~V}$ are used. However, the lower the voltage, the more acceptable the treatment is.

Moreover, lower voltage is preferable from the viewpoint of avoiding thermal denaturation owing to Joule heating because the greatest advantage of IRE therapy is the mechanism of cell ablation without thermal damage to the surrounding tissue. The American National Standard for Electrosurgical Devices identifies the increase in skin temperature by $12 \mathrm{~K}$ as a potential hazard, based on the normal skin temperature of $29-33^{\circ} \mathrm{C}$ and a long-term skin burn threshold of $45^{\circ} \mathrm{C}$ (Prausnitz, 1996). However, thermal damage is accumulated as a function of not only the temperature, but also the exposure time to that temperature. We have recently developed a direct method to measure the temperature rise of a tissue phantom and the corresponding protein denaturation during IRE by using a temperature-sensitive ink and Raman spectroscopic measurement (Kurata et al., 2017). In this method, the color of the temperature-sensitive ink starts fading at $53.5^{\circ} \mathrm{C}$ and completely disappears at $57.7^{\circ} \mathrm{C}$. Using the ink mixed in agarose gel, our previous study showed that the change in the color caused by the application of electric pulses reflected the induction of thermal denaturation of protein. This method was applied to evaluate the risk of thermal damage during contact IRE. The result showed that no change in color was observed when a tissue phantom with ink was exposed to the electric pulses under the same conditions as those used in cell experiments. The experimental result indicates that no obvious thermal damage is induced as long as these pulse parameters are selected. This is because temperature promptly elevated owing to Joule heating, but the heat dissipates during the subsequent long interval. In order to avoid thermal damage to a targeted tissue, it is important to determine the optimal setting of pulse parameters before the contact IRE therapy.

\section{Conclusions}

The feasibility of a comb-shaped miniature electrode in the order of sub-millimeter was examined for reducing the required voltage for IRE. A $150-\mu \mathrm{m}$-wide electrode with a $100-\mu \mathrm{m}$ gap between its teeth successfully ablated the cells at the surface of the tissue phantom by the application of repetitive electric pulses at $100 \mathrm{~V}$. The maximum ablation depth was $72.7 \mu \mathrm{m}$; however, further studies are required to maximize the ablation depth under the constraint of limited applied voltage.

\section{Acknowledgements}

This study was supported by JSPS KAKENHI Grant Number 25670887 and 26249021. The authors wish to acknowledge Dr. J. J. Cannon for critical reading of the manuscript.

\section{References}

Abidor, I.G., Arakelyan, V.B., Chernomordik, L.V., Chizmadzhev, Y.A., Pastushenko, V.F., Tarasevich, M.R., 246 Electric Breakdown of Bilayer Lipid Membranes I. The Main Experimental Facts and Their Qualitative Discussion, Bioelectrochemistry and Bioenergetics, Vol.6, (1979), pp. 37-52.

Ball, C., Thomson, K.R., Kavnoudias, H., Irreversible Electroporation: A New Challenge in "out of Operating Theater" Anesthesia, Anesthesia and Analgesia, Vol.110, No.5 (2010), pp. 1305-1309.

Baust, J., Gage, A.A., Ma, H., Zhang, C.M., Minimally Invasive Cryosurgery--Technological Advances, Cryobiology, Vol.34, No.4 (1997), pp. 373-384.

Bernstein, T., Electrical Injury: Electrical Engineer's Perspective and an Historical Review, Annals of the New York Academy of Sciences, Vol.720, (1994), pp. 1-10.

Brace, C.L., Radiofrequency and Microwave Ablation of the Liver, Lung, Kidney, and Bone: What Are the Differences?, Current Problems in Diagnostic Radiology, Vol.38, No.3 (2009), pp. 135-143.

Davalos, R.V., Mir, I.L., Rubinsky, B., Tissue Ablation with Irreversible Electroporation, Annals of Biomedical 
Engineering, Vol.33, No.2 (2005), pp. 223-231.

Dubinsky, T.J., Cuevas, C., Dighe, M.K., Kolokythas, O., Hwang, J.H., High-Intensity Focused Ultrasound: Current Potential and Oncologic Applications, AJR. American Journal of Roentgenology, Vol.190, No.1 (2008), pp. 191-199.

Fromm, M.E., Taylor, L.P., Walbot, V., Stable Transformation of Maize after Gene-Transfer by Electroporation, Nature, Vol.319, No.6056 (1986), pp. 791-793.

Gage, A.A. and Baust, J., Mechanisms of Tissue Injury in Cryosurgery, Cryobiology, Vol.37, No.3 (1998), pp. 171-186.

Garcia-Sanchez, T., Guitart, M., Rosell, J., Gomez-Foix, A.M., Bragos, R., Automatic System for Electroporation of Adherent Cells Growing in Standard Multi-Well Plates, Conf Proc IEEE Eng Med Biol Soc, Vol.2012, (2012), pp. 2571-2574.

Garcia-Sanchez, T., Guitart, M., Rosell-Ferrer, J., Gomez-Foix, A.M., Bragos, R., A New Spiral Microelectrode Assembly for Electroporation and Impedance Measurements of Adherent Cell Monolayers, Biomedical Microdevices, Vol.16, No.4 (2014), pp. 575-590.

Glaser, R.W., Leikin, S.L., Chernomordik, L.V., Pastushenko, V.F., Sokirko, A.I., Reversible Electrical Breakdown of Lipid Bilayers: Formation and Evolution of Pores, Biochimica et Biophysica Acta: Protein Structure and Molecular Enzymology, Vol.940, No.2 (1988), pp. 275-287.

Jastreboff, M.M., Sokoloski, J.A., Bertino, J.R., Narayanan, R., Use of Electroporation to Study the Cytotoxic Effects of Fluorodeoxyuridylate in Intact-Cells, Biochemical Pharmacology, Vol.36, No.8 (1987), pp. 1345-1348.

Kinosita, K., Jr., Ashikawa, I., Saita, N., Yoshimura, H., Itoh, H., Nagayama, K., Ikegami, A., Electroporation of Cell Membrane Visualized under a Pulsed-Laser Fluorescence Microscope, Biophysical Journal, Vol.53, No.6 (1988), pp. 1015-1019.

Koumbourlis, A.C., Electrical Injuries, Critical Care Medicine, Vol.30, No.11 Suppl (2002), pp. S424-430.

Kurata, K., Yoshii, T., Deguchi, Y., Takamatsu, H., Raman Microspectroscopic Detection of Thermal Denaturation Associated with Irreversible Electroporation, International Journal of Heat and Mass Transfer, Vol.111, (2017), pp. 163-170.

Kurata, K., Yoshii, T., Uchida, S., Fukunaga, T., Takamatsu, H., Visualization of Electroporation-Induced Temperature Rise Using Temperature-Sensitive Ink, International Journal of Heat and Mass Transfer, Vol.55, No.23-24 (2012), pp. 7207-7212.

Mazzoleni, A.P., Sisken, B.F., Kahler, R.L., Conductivity Values of Tissue Culture Medium from 20 Degrees C to 40 Degrees C, Bioelectromagnetics, Vol.7, No.1 (1986), pp. 95-99.

Melikov, K.C., Frolov, V.A., Shcherbakov, A., Samsonov, A.V., Chizmadzhev, Y.A., Chernomordik, L.V., Voltage-Induced Nonconductive Pre-Pores and Metastable Single Pores in Unmodified Planar Lipid Bilayer, Biophysical Journal, Vol.80, No.4 (2001), pp. 1829-1836.

Mir, L.M., Orlowski, S., Belehradek, J., Jr., Paoletti, C., Electrochemotherapy Potentiation of Antitumour Effect of Bleomycin by Local Electric Pulses, European Journal of Cancer, Vol.27, No.1 (1991), pp. 68-72.

Murat, F.J., Poissonnier, L., Pasticier, G., Gelet, A., High-Intensity Focused Ultrasound (Hifu) for Prostate Cancer, Cancer Control, Vol.14, No.3 (2007), pp. 244-249.

Neumann, E., Schaeferridder, M., Wang, Y., Hofschneider, P.H., Gene-Transfer into Mouse Lyoma Cells by Electroporation in High Electric-Fields, EMBO Journal, Vol.1, No.7 (1982), pp. 841-845.

Polak, A., Bonhenry, D., Dehez, F., Kramar, P., Miklavcic, D., Tarek, M., On the Electroporation Thresholds of Lipid Bilayers: Molecular Dynamics Simulation Investigations, Journal of Membrane Biology, Vol.246, No.11 (2013), pp. 843-850.

Prausnitz, M.R., The Effects of Electric Current Applied to Skin: A Review for Transdermal Drug Delivery, Advanced Drug Delivery Reviews, Vol.18, No.3 (1996), pp. 395-425.

Quaglino, P., Mortera, C., Osella-Abate, S., Barberis, M., Illengo, M., Rissone, M., Savoia, P., Bernengo, M.G., Electrochemotherapy with Intravenous Bleomycin in the Local Treatment of Skin Melanoma Metastases, Annals of Surgical Oncology, Vol.15, No.8 (2008), pp. 2215-2222.

Riemann, F., Zimmermann, U., Pilwat, G., Release and Uptake of Haemoglobin and Ions in Red Blood Cells Induced by Dielectric Breakdown, Biochimica et Biophysica Acta: Protein Structure and Molecular Enzymology, Vol.394, No.3 (1975), pp. 449-462.

Riggs, C.D. and Bates, G.W., Stable Transformation of Tobacco by Electroporation - Evidence for Plasmid Concatenation, Proceedings of the National Academy of Sciences of the United States of America, Vol.83, No.15 (1986), pp. 5602-5606.

Roberts, D., 50-V Shock Hazard Threshold, IEEE Transactions on Industry Applications, Vol.46, No.1 (2010), pp. 102-107.

Sale, A.J. and Hamilton, W.A., Effects of High Electric Fields on Micro-Organisms: Iii. Lysis of Erythrocytes and Protoplasts, Biochimica et Biophysica Acta: Protein Structure and Molecular Enzymology, Vol.163, No.1 (1968), 
pp. 37-43.

Teissie, J. and Rols, M.P., An Experimental Evaluation of the Critical Potential Difference Inducing Cell Membrane Electropermeabilization, Biophysical Journal, Vol.65, No.1 (1993), pp. 409-413.

Thomson, K.R., Cheung, W., Ellis, S.J., Federman, D., Kavnoudias, H., Loader-Oliver, D., Roberts, S., Evans, P., Ball, C., Haydon, A., Investigation of the Safety of Irreversible Electroporation in Humans, Journal of Vascular and Interventional Radiology, Vol.22, No.5 (2011), pp. 611-621.

Zimmermann, U., Pilwat, G., Riemann, F., Dielectric Breakdown of Cell Membranes, Biophysical Journal, Vol.14, No.11 (1974), pp. 881-899. 